\title{
Supported Housing and Supported Independent Living in the Netherlands, with a Comparison with England
}

\author{
Charlotte de Heer-Wunderink • Ellen Visser • \\ Annemarie Caro-Nienhuis $\cdot$ Sjoerd Sytema $\cdot$ \\ Durk Wiersma
}

Received: 9 April 2010/Accepted: 3 January 2011/Published online: 19 January 2011

(C) The Author(s) 2011. This article is published with open access at Springerlink.com

\begin{abstract}
Research into community housing programs for people with severe mental illness is underexposed. The Dutch UTOPIA study describes characteristics of their service users, which may predict their allocation to either supported housing or supported independent living programs. Additionally, a comparison is made with English studies. 119 Care coordinators of Dutch residential care institutes and 534 service users participated in a crosssectional survey which includes socio-demographic data, clinical data, measures of functioning, needs for care and quality of life. Differences between Dutch residents and independent living service users were small, making predictions of care allocation difficult. This similarity suggests a possible lack of methodical assessment in the allocation procedure of people who are eligible for residential housing or independent living programs. This is largely comparable to the English situation. In comparison with their English counterparts, Dutch service users have more met needs and are more engaged in occupational activities.
\end{abstract}

Keywords Community mental health care .

Residential care - Supported housing .

Supported independent living · Care allocation

C. de Heer-Wunderink $(\bowtie) \cdot$ E. Visser · A. Caro-Nienhuis .

S. Sytema - D. Wiersma

University Medical Centre Groningen (UMCG),

University of Groningen, PO Box 30.001, CC 72,

9700 RB Groningen, The Netherlands

e-mail: c.de.heer@med.umcg.nl

\section{Introduction}

In Europe, people with severe mental illnesses (SMI) are more and more allocated to community housing programs, such as supported housing and supported independent living (Fakhoury et al. 2002). Supported housing includes permanent and supervised housing in residential facilities which are owned by a mental health service in the community. People who are not related to each other, but all cope with impairments due to psychiatric problems live together in these facilities. Supported independent living provides support in the home of an individual with SMI, who lives on his own or with a partner, friend or family members.

Research into these programs and the characteristics, functioning and quality of life of its' service users is limited. Recently, Priebe et al. (2009) conducted a study into different housing programs in England. They found a considerable overlap of characteristics of service users and care provision between housing services of supported housing and supported independent living. This brings the current system of allocation of people with SMI to such housing programs up for discussion. Priebe et al. raise the question whether their care allocation system benefits from the flexibility to provide the right care to individuals, taking their specific situation and needs for care into account, or that the system lacks objective criteria. These criteria are needed to guarantee a methodical and structural assessment of potential service users with a certain amount of objectivity in allocating people to an appropriate level of care.

The present study (which is part of the UTOPIA study; de Heer-Wunderink et al. 2008), including a random sample of 119 Dutch care coordinators and 534 service users of community housing programs, looks into the allocation system of Dutch community housing programs. 
This study describes the socio-demographic and clinical characteristics of service users of supported housing (residential care) and supported independent living programs, their prediction of allocation to either type of care and the association between type of care and social participation, needs for care and quality of life. A comparison is made with two English studies (Priebe et al. 2009; Slade et al. 2005) in order to discuss the (dis)similarities between both countries which differ greatly in process and outcome of deinstitutionalization.

\section{Methods}

Setting

In The Netherlands, 21 Dutch Regional Institutes for Residential Care (RIRC, Dutch acronym RIBW), provide supported housing and supported independent living in the community for people with SMI.

The exceptional medical expenses act funds the care provision of RIRCs. The eligibility of an individual for these services is assessed by the so-called 'center for indications for care' (CIC). The application for supported housing and supported independent living can be carried out by the person concerned or by any health care professional, e.g., a general practitioner (GP) or a psychiatrist. The CIC gathers information about the individual applicant and his situation, e.g., by interviewing this person and retrieving information from his GP or specialist. Supported housing is allocated when the CIC concludes that the applicant has a psychiatric impairment, and needs a protective living environment and/or permanent supervision. Supported independent living is allocated when the person suffers from moderate or severe impairments in the area of social independence, psychiatric functioning, cognitive skills or moderate or severe behavioral problems, without the need for a protective living environment and permanent supervision.

RIRCs have explicitly distinguished themselves from hospital-based long stay facilities in their focus of care. Where the latter focus primarily on reducing psychiatric symptoms, the first are mainly concerned with the service users' daily living, rehabilitation and participation in society. This reflects on their community housing facilities, which are mainly one-family homes, providing single bedrooms and a shared living room, kitchen and bathroom for (in general) four residents per home. Furthermore, the number of small-scale housing facilities, especially individual apartments for one or two (sometimes related) individuals, has increased in the last 5 years. RIRCs also manage day centers, sheltered employment projects and offer job coaching to stimulate occupational participation.
All residents receive support from a care coordinator, who is skilled in the psychiatric rehabilitation approach (Anthony et al. 2002; Anthony and Farkas 2009). The most important aspects of this approach in this context are the equality of the therapeutic relationship and the special focus on goal setting, which is guided by the service users' own wishes and choices. RIRCs, with one exception, do not exclude people who cope with substance abuse. This group of service users and also other groups with specific problems such as deaf people with SMI, children under 18, people suffering from autism and mothers with children, are often provided with care in specific facilities and/or by care coordinators who have been trained to work with these people.

In 2007, 11,427 Dutch people received supported housing in the community (Van Hoof et al. 2009). Roughly half of them received this type of community care from mental health institutes (mostly former mental hospitals); the other half received supported housing in the community from RIRCs. In addition, the RIRCs also provided support and counseling to 6,797 people in supported independent living.

All RIRCs were invited to participate in a cross-sectional survey of a random sample of care coordinators and their patients, but 16 of the 21 institutes actually took part in the study. All care coordinators met the following criteria: employed for at least $24 \mathrm{~h} /$ week for at least 1 year to guarantee familiarity with the organization and the way of counseling (trained in the psychiatric rehabilitation approach; Anthony et al. 2002; Anthony and Farkas 2009), and involved with the day-to-day care of the service users. From a total of 1,275 care coordinators, 119 (9\%) were selected to ensure a minimal mean number of 40 participating service users per RIRC. They initially approached 1,432 service users of whom $818(57 \%)$ gave their written informed consent. Only participants with complete data records $(n=534,65 \%)$ were included in this study. Participants and non-participants did not differ on gender, age, type or length of care/support (RIRC) in years, psychiatric diagnosis, comorbidity of substance abuse or a personality disorder.

The study was discussed with the secretary of the medical ethics committee of the University Medical Center Groningen and considered to not require formal approval by the full committee.

\section{Instruments}

Service users filled in a socio-demographic data questionnaire and the Manchester short assessment of quality of life (MANSA; Priebe et al., 1999). The MANSA consists of 4 objective questions to be answered with yes or no and 12 subjective questions rated on a scale between 1 (could not 
be worse) and 7 (could not be better) about satisfaction with life as a whole, friendships, accommodation, the financial situation, etc. In the present study, the mean item score of the 12 subjective questions is used, where a higher mean item score reflects a better quality of life. Cronbach's alpha of the satisfaction ratings is 0.74 (Priebe et al. 1999). Clinical data were gathered from the care coordinator.

Level of functioning was determined by the health of the nation outcome scales (HoNOS; Wing et al. 1998), comprising 12 domains of functioning which are rated by care coordinators on a scale between 0 (no problem) to 4 [(very) severe problem]. The total mean HoNOS score, which is used in this study, is the mean sum of the scores on 12 domains. Intraclass correlation coefficients for the individual items and the total score were between 0.74 and 0.88 , except for the item of aggression (icc $=0.61$ ) (Wing et al. 1998). The service users were divided into groups based on their level of functioning (based on the division used by Parabiaghi et al. 2005): (1) a group with no to mild problems (maximum score 2 on at least one item): $38 \%$; (2) a group with (very) severe problems (score 3 or 4 on at least one item): $62 \%$.

The Camberwell assessment of need short appraisal schedule (CANSAS; Phelan et al. 1995) was used to establish care coordinator rated needs for care. It comprises 22 items concerning social and health needs. Needs are rated on a three point scale: $0=$ no need, $1=$ a met need [a problem which is (at least largely) solved by an intervention] and $2=$ an unmet need (a problem has not been solved, either because there is no intervention or the applied intervention is not sufficient). The total number of needs (maximum 22) is the sum of all met and unmet needs. Inter-rater correlation and test-retest correlation of the total number of needs were 0.99 and 0.78 , respectively, as assessed by Phelan et al. (1995).Housing needs were not taken into account since most people in residential care had a met need. Met and unmet needs were grouped into the four following domains: (1) activities of daily living (food, self-care and looking after the home); (2) mental health care (physical health, psychotic symptoms, information on medication, psychological distress, safety to self and others, alcohol and drugs); (3) rehabilitation (daytime activities, company, intimate relationships, sexual expression and child care); and (4) services (education, telephone, transport, money and benefits). All care coordinators were trained in the use of these instruments.

\section{Data Analysis}

Univariate tests were performed to establish statistically significant differences between residents in supported housing and people in supported independent living programs. Associations between normally distributed variables were determined by Pearson's correlation coefficient; the Kendall's Tau-b correlation coefficient was calculated for associations between non-parametric variables. Logistic regression analysis was carried out to determine associations between patient characteristics and the type of care received. Only variables that showed significant differences between groups in the univariate tests were included in the logistic model.

Logistic regression analysis was also used to determine whether level of functioning [(very) severe functional problems vs. no to mild functional problems] was associated with differences in employment status, type of housing (supported housing or supported independent living), the nature of met and unmet needs for care and satisfaction (as measured with the MANSA) with life as a whole, daily activities, physical and mental health status, and the relationship with partner and family.

Data from the study of Priebe et al. (2009) and of Slade et al. (2005) were used to compare Dutch residents and Dutch service users receiving supported independent living to their English counterparts. Dutch independently living service users were compared to English people receiving so-called 'floating support' (Priebe et al. 2009). Although different terms are used, these housing programs seem to be comparable. They both seek to maintain an independent living situation and to develop living skills for people with SMI. However, supported independent living is provided for an indefinite period of time, whereas floating support is restricted to a period of-in general-less than 2 years. Since a large part of Dutch people in supported independent living receive this support for less than 4 years, the actual differences in the length of care provision between these programs are probably relatively small. Floating support will be further referred to as supported independent living. The study of Slade et al. concerns a sample of service users of community mental health teams, who are similar to the participants in the study of Priebe et al. in supported housing and supported independent living on age and diagnosis of schizophrenia, but not on gender (participants in the study of Slade et al. are more likely to be female).

\section{Results}

Socio-Demographic and Clinical Characteristics

In The Netherlands, residents in supported housing are more often male $\left(\chi^{2}=9.632, P=0.002\right)$ and lower educated $\left(\chi^{2}=15.933, P<0.001\right)$ than service users in supported independent living programs (Table 1). Residents in supported housing are also more likely to be diagnosed with schizophrenia or related disorders $\left(\chi^{2}=17.588\right.$, $P<0.001)$, to cope with substance abuse $\left(\chi^{2}=6.647\right.$, 
$P=0.010)$ and to reside in the current RIRC for more than 6 years $\left(\chi^{2}=8.005, P=0.005\right)$. People in supported independent living are more often diagnosed with mood and anxiety disorders $\left(\chi^{2}=13.261, P<0.001\right)$. Surprisingly, the mean total HoNOS score is not different between both groups, and neither are the proportions of people with (very) severe problems (63\% for residents vs. 57\% for independently living service users).

A logistic regression analysis (supported housing vs. supported independent living) revealed that being male (OR 1.644, $P=0.011$ ), a lower educational level (OR 2.524, $P=0.001$ ), a diagnosis of schizophrenia (OR $1.742, P=0.006)$ and length of care for more than 6 years (OR 1.534, $P=0.049$ ) significantly predicted allocation to supported housing. However, the odds ratio's indicated that the differences between both groups were relatively small.

\section{Social Participation, Needs for Care and Quality of Life}

More than half of Dutch residents in supported housing have paid or sheltered/voluntary employment, which is more or less similar to the independently living service users. Nearly half of the residents attend a day centre, where this is only the case for a third of the independently living service users $\left(\chi^{2}=11.355, P=0.001\right)$. As for social contacts, residents in supported housing are less likely to report a friendly contact in the past week than independently living service users $\left(\chi^{2}=6.905, P=0.009\right)$.

The difference between the two groups as to met needs was statistically significant: residents were assigned a higher total mean number of met needs (Mann-Whitney $Z=-5.470, P<0.001$ ), as well as a higher total mean number of met needs for three of the four domains. In the area of rehabilitation the total mean number of met needs did not differ. No differences were found between residents and independently living service users as to the total mean number of unmet needs and the total mean numbers of unmet needs for the four separate domains.

The quality of life as measured with the MANSA did not differ much between both Dutch groups, although the total mean item score reported by residents was somewhat higher $(t=2.032, d f=532, P=0.043)$. On the 7-pointsscale only a slightly higher than average satisfaction with various aspects of life was reported. Quality of life appeared to be negatively associated with unmet needs (Kendall's Tau-b $=-0.265, P<0.001$ ), which is in agreement with other studies (Wiersma and Van Busschbach 2001; Slade et al. 2004).

A logistic regression analysis revealed that all these factors (attending a day centre (OR 1.931, $P=0.001$ ), number of met needs more than total mean number of met needs (OR 2.533, $P<0.001$ ) and a higher quality of life (OR 1.529, $P=0.026$ ) were significantly associated with supported housing. Having had a friendly contact in the past week was significantly associated with independent living with support (OR 1.762, $P=0.011)$.

A comparison between the two groups of Dutch service users revealed that users with (very) severe problems (score 3 or 4 on at least one HoNOS item) differ from those with no to mild problems (maximum score 2 on at least one item) on the number of unmet as well as met needs. The first were more likely to have a higher number of unmet needs in the domains of activities of daily living [mean 0.23 (SD 0.575) vs. mean 0.04 (SD 0.219); $\mathrm{OR}=2.604, P=0.014$ ], mental health care [mean 0.81 (SD 1.095) vs. mean 0.17 (SD 0.537); $\mathrm{OR}=2.400, P<0.001$ ] and services [mean 0.28 (SD 0.564) vs. mean 0.08 (sd 0.305); $\mathrm{OR}=1.994$, $P=0.019)$. They were also more likely to have more met needs in the domains of mental health care [mean 2.50 (SD 1.345 ) vs. mean 2.20 (sd 1.179); $\mathrm{OR}=1.210, P=0.044]$ and services [mean 1.56 (SD 1.228) vs. mean 1.15 (SD 1.084); OR 1.296, $P=0.012$ ]. No differences were found regarding employment status, type of housing (supported housing or supported independent living), and satisfaction (as measured with the MANSA) with life as a whole, daily activities, physical and mental health status and the relationship with a partner and their family.

\section{Dutch and English Residents and People in Supported} Independent Living Programs Compared

Table 1 shows that English people in supported housingcompared to the Dutch-are more often male $\left(\chi^{2}=8.04\right.$, $P=0.005)$, of equal age, more often unmarried $\left(\chi^{2}=38.7, P<0.001\right)$, less likely to be involved in paid $\left(\chi^{2}=4.06, \quad P=0.044\right)$ and voluntary or sheltered employment $\left(\chi^{2}=19.8, P<0.001\right)$ and equally active in attending a day centre. They are more often diagnosed with schizophrenia $\left(\chi^{2}=3.86, P=0.050\right)$, have a comparable total mean number of needs, but a higher number of unmet needs. ${ }^{1}$ The ratio between met and unmet needs for the four separate domains shows that English residents have less met needs and more unmet needs in all these areas.

Differences between English and Dutch service users receiving supported independent living tend in the same direction: the first are more likely to be male $\left(\chi^{2}=10.8\right.$, $P=0.001)$, less often married $\left(\chi^{2}=20.9, P<0.001\right)$, equally involved in paid employment but less likely to be involved in voluntary or sheltered employment $\left(\chi^{2}=29.2\right.$, $P<0.001)$, more likely to attend a day centre $\left(\chi^{2}=4.73\right.$, $P=0.030)$, more often diagnosed with schizophrenia $\left(\chi^{2}=8.9, P=0.003\right)$, but are of the same age, and have

\footnotetext{
${ }^{1}$ A statistical test could not be performed, because standard deviations of the total mean number of (un)met needs in the study of Priebe et al. (2009) were not reported.
} 
Table 1 Socio-demographic and clinical characteristics of residents in supported housing and service users receiving supported independent living

\begin{tabular}{|c|c|c|c|c|}
\hline & \multicolumn{2}{|l|}{ The Netherlands } & \multicolumn{2}{|l|}{ England $^{\mathrm{a}}$} \\
\hline & $\begin{array}{l}\text { Supported housing } \\
(n=332)\end{array}$ & $\begin{array}{l}\text { Supported independent } \\
\text { living }(n=202)\end{array}$ & $\begin{array}{l}\text { Supported housing } \\
(n=175)\end{array}$ & $\begin{array}{l}\text { Supported independent } \\
\text { living }(n=66)\end{array}$ \\
\hline Males (\%) & 62 & 48 & 74 & 71 \\
\hline Age, mean (SD) & $43.1(14.6)$ & $43.8(12.1)$ & $43.9(11.8)$ & $43.1(12.5)$ \\
\hline Never married $(\%)$ & 71 & 72 & 95 & 98 \\
\hline \multicolumn{5}{|l|}{ Education $(\%)$} \\
\hline$\leq$ primary school & 24 & 10 & - & - \\
\hline Lower/moderate vocational & 56 & 59 & - & - \\
\hline Higher voc./(pre)university & 20 & 30 & - & - \\
\hline \multicolumn{5}{|l|}{ Diagnosis $(\%)$} \\
\hline Schizophrenia & 50 & 31 & 59 & 52 \\
\hline Mood/anxiety disorders & 22 & 36 & 19 & 26 \\
\hline Substance abuse $(\%)$ & 31 & 21 & 29 & 26 \\
\hline Personality disorder $(\%)$ & 35 & 41 & - & - \\
\hline Total mean HoNOS score (SD) & $11.7(6.0)$ & $11.6(6.7)$ & - & - \\
\hline \multicolumn{5}{|l|}{ Length of stay/provided support (\%) } \\
\hline $0-4$ years & 49 & 58 & - & - \\
\hline $4-6$ years & 17 & 19 & - & - \\
\hline$>6$ years & 34 & 23 & - & - \\
\hline \multicolumn{5}{|l|}{ Occupational activity (\%) } \\
\hline Unemployed & 45 & 42 & - & - \\
\hline Paid employment & 7 & 12 & 3 & 8 \\
\hline Voluntary/sheltered employment $^{\mathrm{c}}$ & 48 & 46 & 28 & 16 \\
\hline Attending day centre (\%) & 47 & 32 & 42 & 47 \\
\hline Spoken to a friend in the past week $(\%)$ & 69 & 80 & - & - \\
\hline \multicolumn{5}{|l|}{ Needs (met/unmet needs) } \\
\hline Total mean number of met/unmet needs & $6.7 / 1.6$ & $5.5 / 1.8$ & $4.4 / 3.1$ & $4.5 / 3.0$ \\
\hline \multicolumn{5}{|l|}{ Domains of need, mean number met/unmet } \\
\hline Activities of daily living & $1.3 / 0.2$ & $0.9 / 0.2$ & $0.8 / 0.5$ & $0.7 / 0.5$ \\
\hline Mental health care & $2.5 / 0.6$ & $2.1 / 0.6$ & $2.1 / 0.9$ & $2.4 / 0.7$ \\
\hline Rehabilitation & $1.3 / 0.7$ & $1.4 / 0.8$ & $0.7 / 1.1$ & $0.5 / 1.4$ \\
\hline Services & $1.6 / 0.2$ & $1.1 / 0.2$ & $0.9 / 0.6$ & $0.8 / 0.5$ \\
\hline MANSA mean item score $(\mathrm{SD})^{\mathrm{b}}$ & $4.5(1.3)$ & $4.3(1.2)$ & $\begin{array}{l}4.3(1.0) \\
(n=101)^{\mathrm{b}}\end{array}$ & $\begin{array}{l}4.3(1.0) \\
(n=101)^{\mathrm{b}}\end{array}$ \\
\hline
\end{tabular}

-, Data are not available in the reported studies

a Data derived from Priebe et al. (2009), except for variables marked with b data derived from Slade et al. (2005)

c From Priebe et al. (2009) the number of service users involved in 'occupational activities provided by the service' were added to this category for comparability with the Dutch service users. English 'involvement in community activities' was not taken into account, because the actual activities concerned were not described and did not seem to involve either paid, supported or voluntary employment

roughly the same total number of needs although more unmet needs (See footnote 1). Regarding the ratio between met and unmet needs for the four separate domains, Table 1 shows that in the domain of mental health care English independently living service users have slightly more met needs than their Dutch counterparts and a comparable number of unmet needs. The difference in quality of life between both groups is small.

\section{Discussion}

The results of the present study, focusing on the (dis)similarities between people with SMI in supported housing and supported independent living programs in The Netherlands, reveal that differences between these two groups are much smaller than one would expect. Participation in occupational activities, attending a day centre, number of (unmet) 
needs and quality of life do not differ greatly. This calls the Dutch allocation system to housing programs into question: are we dealing with a flexible system that contributes to positive outcomes for individuals, or is there a lack of methodical assessment of people with SMI when applying for either supported housing or supported independent living in the community? For instance, more than one-third of Dutch residents in supported housing have at most mild functional problems according to their HoNOS scores. This suggests that at least a part of these people might currently receive a higher level of care than is actually required, and perhaps also wished for by residents themselves. This is a pressing issue, taking the long and persisting waiting lists for this type of care into account.

We did find differences between the number of unmet and met needs of Dutch service users with different levels of functioning, regardless of type of housing program. In the domains of mental health care and services, people coping with (very) severe problems not only have more met needs than people with no to mild problems, but also more unmet needs. Although care is provided, some needs in these domains remain difficult to meet. For example, prescribed antipsychotics can reduce psychotic symptoms, but at the same time can cause hindering side effects. In the area of activities of daily living, people with severe impairments also have more unmet needs.

The composition of the service user population in supported housing and supported independent living in England differs to some extent to that in The Netherlands, e.g., with respect to gender (more males), civil status (more persons who have never been married) and diagnosis (more persons with schizophrenia). This suggests that the English service users possibly are more similar to the long stay population from the closed or reduced mental hospitals. Deinstitutionalization in The Netherlands has taken place at a much slower pace, if at all, and has resulted since the 90s in an increase of small scale residential facilities in the community. These facilities are open not only for people residing in the mental hospital but also for those who never entered such a long stay trajectory. Despite these different deinstitutionalization processes, the overall effect on the people with SMI in housing programs seems small. However, we did find differences in the extent to which English and Dutch service users participate in occupational activities. In The Netherlands, participation rates are much higher. This might be a consequence of the similarity of English service users-more than the Dutch service users - to the long stay population of mental hospitals. Furthermore, Dutch governmental policy in the 90s created possibilities for RIRCs to invest in the development of projects concerning occupational activities. This has resulted in a wide range of projects with different levels of structure and demands for participation offered by RIRCs, e.g., day centers, sheltered employment projects and job coaching. It is not clear if English service providers have similar facilities.

Although English and Dutch service users in supported housing and supported independent living have a comparable total number of needs, the English have a lower number of met needs. Only in the mental health care domain, English people in supported independent living have slightly more met needs. This can be seen as a small but further confirmation of the more chronic nature of the psychiatric problems of English service users. Another (perhaps additional) explanation can be the policy of Dutch RIRCs to distinguish themselves from the mental hospital, in not providing psychiatric treatment. This may have consequences for the way psychiatric problems are dealt with by care coordinators, who perhaps lack skills to observe and monitor these problems properly. However, differences in unmet needs for this domain are negligible. Overall, it seems that Dutch community care may be more able to address the needs of their service users, though more information is needed about the level of functioning of the English service users to substantiate these findings.

One should be aware of some limitations in the reported studies. Our study and those of Priebe et al. and Slade et al. have a cross-sectional design, which entails that relationships between cause and effect cannot adequately be determined. Furthermore, the participants in the study of Slade et al. are slightly different (more females) from that in the study of Priebe et al.

Comparisons between housing programs in different countries are difficult. Descriptions of residential facilities and the care they provide vary in their characteristics and terminology. For example, in the present study the Dutch supported independent living program is compared to the English floating support program. They seem to be similar programs, except for the latter program to be limited to a fixed period of time whereas the first-in principle-is provided indefinitely. This could be a limitation to the strength of this comparison. To further establish the (dis)similarities between quality and nature of the community housing programs in The Netherlands and England (and in other countries that experienced deinstitutionalization) in depth research into among other things the independency of living space (e.g., in The Netherlands all residents in supported housing have their own bedroom), autonomy of residents and the scale of residential homes is needed. In these comparative studies, it is also important to take into account some contextual factors, such as social policy regarding employment of people with SMI, economic factors and access to healthcare.

Finally, Dutch hospital based mental health institutions also provide supported housing and supported independent living programs in the community, but these facilities were 
not taken into account. A comparative study between supported housing and supported independent living provided by hospital-based facilities versus RIRCs is needed in the future.

Open Access This article is distributed under the terms of the Creative Commons Attribution Noncommercial License which permits any noncommercial use, distribution, and reproduction in any medium, provided the original author(s) and source are credited.

\section{References}

Anthony, W., Cohen, M., Farkas, M., \& Gagne, C. (2002). Psychiatric rehabilitation. Boston: Boston University Center for Psychiatric Rehabilitation.

Anthony, W. A., \& Farkas, M. D. (2009). Primer on the psychiatric rehabilitation process. Boston: Boston University Center for Psychiatric Rehabilitation.

De Heer-Wunderink, C., Caro-Nienhuis, A. D., Sytema, S., \& Wiersma, D. (2008). Residential care: Dutch and Italian residents of residential care facilities compared. Epidemiologia e Psichiatria Sociale, 17, 162-165.

Fakhoury, W. K. H., Murray, A., Shepherd, G., \& Priebe, S. (2002). Research in supported housing. Social Psychiatry and Psychiatric Epidemiology, 37, 301-315.

Parabiaghi, A., Barbato, A., D’Avanzo, B., Erlicher, A., \& Lora, A. (2005). Assessing reliable and clinically significant change on health of the nation outcome scales: Method for displaying longitudinal data. Australian and New Zealand Journal of Psychiatry, 39, 719-725.
Phelan, M., Slade, M., Thornicroft, G., Dunn, G., Holloway, F., Wykes, T., et al. (1995). The Camberwell assessment of need: The validity and reliability of an instrument to assess the needs of people with severe mental illness. British Journal of Psychiatry, 167, 589-595.

Priebe, S., Huxley, P., Knight, S., \& Evans, S. (1999). Application and results of the Manchester short assessment of quality of life (Mansa). International Journal of Social Psychiatry, 45, 7-12.

Priebe, S., Saidi, M., Want, A., Mangalore, R., \& Knapp, M. (2009). Housing services for people with mental disorders in England: Patient characteristics, care provision and costs. Social Psychiatry and Psychiatric Epidemiology, 44, 805-814.

Slade, M., Leese, M., Cahill, S., Thornicroft, G., \& Kuipers, E. (2005). Patient-rated mental health needs and quality of life improvement. British Journal of Psychiatry, 187, 256-261.

Slade, M., Leese, M., Ruggeri, M., Kuipers, E., Tansella, M., et al. (2004). Does meeting needs improve quality of life? Psychotherapy and Psychosomatics, 73, 183-189.

Van Hoof, F, Knispel, A, Van Wijngaarden, B, \& Kok, I. (2009). Toekomstverkenning intramurale GGZ Utrecht: Trimbosinstituut.

Wiersma, D., \& van Busschbach, J. (2001). Are needs and satisfaction of care associated with quality of life? An epidemiological survey among the severely mentally ill in The Netherlands. European Archives of Psychiatry and Clinical. Neuroscience, 251, 239-246.

Wing, J. K., Wing, J. K., Beevor, A. S., Curtis, R. H., Park, S. B. G., Hadden, S., et al. (1998). Health of the nation outcome scales (HoNOS): Research and development. British Journal of Psychiatry, 172, 11-18. 